\title{
Educação intercultural no Brasil: entre o conservadorismo e transformações radicais ${ }^{1}$
}

Universidade de Genebra (Genebra, Suíça)
Resumo: Este artigo procura analisar o surgimento da educação intercultural no sistema educacional brasileiro. Primeiro, sintetizamos o debate internacional no campo da educação intercultural. Em segundo lugar, buscamos traçar o desenvolvimento das relações interétnicas no Brasil. Descrevese o pesado legado de escravidão e colonização. Em seguida, o artigo trata das medidas legislativas recentemente aprovadas com o propósito de incentivar a inclusão da diversidade cultural na educação. Finalmente, o texto foca nas abordagens interculturais presentes na formação e no exercício profissional dos professores. 0 exemplo brasileiro é interessante pois se caracteriza tanto pelo conservadorismo contínuo que impede a legitimidade intercultural nas escolas quanto, ao mesmo tempo, por um profundo debate sobre identidades culturais e a necessidade de levar todas as desigualdades históricas em consideração.

Palavras-chave: Educação intercultural. Relações étnicas. Desigualdades. Currículo.

Este artigo foi publicado originalmente na revista Prospects, da Unesco, em junho de 2012, com o título "Intercultural education in Brazil: between conservatism and radical transformations". Os direitos foram gentilmente cedidos pelos editores. Tradução de Fernando Effori. 
A primeira parte deste artigo aponta a discussão internacional em curso a respeito do modelo apropriado para lidar com a diversidade cultural. A segunda parte discutirá as relações étnicas e como elas evoluíram no Brasil. Tem-se a impressão de que as abordagens interculturais espelham a forma como essas relações se estruturaram ao longo da história do país, penetraram o sistema de ensino e definiram o lugar dos diferentes grupos no tecido social. A terceira parte será dedicada à forma como a legislação sobre a escola e, em particular, os parâmetros curriculares, introduzem e produzem o interculturalismo em sala de aula. A operacionalização do interculturalismo no Brasil é caracterizada por um componente legal e jurídico significativo. Ao menos no papel, as instruções oficiais parecem enérgicas e inovadoras em termos da atenção à diversidade cultural, étnica e racial. Na última parte, avalia-se o impacto real dos currículos interculturais pretendidos em sala de aula. Examinaremos mudanças recentes no sistema educacional brasileiro voltadas para a introdução de abordagens interculturais na formação e exercício profissional dos professores.

\section{MODELOS CONCORRENTES OU CONVERGÊNCIA INTERNACIONAL}

Todos os observadores dos sistemas educacionais contemporâneos concordam que o tratamento da diversidade cultural representa um desafio tanto para a pesquisa quanto para políticas educacionais. Muitas organizações internacionais, como a Organização das Nações Unidas para a Educação, a Ciência e a Cultura (Unesco), o Conselho Europeu e outros, focam seus programas, projetos e ações nessa questão. Essas organizações também contribuem para a divulgação mundial de abordagens interculturais ou multiculturais em educação.

Em termos de pesquisa, estudos comparativos têm sido publicados nos últimos anos. A legitimidade da perspectiva comparativa tem sido reforçada por análises que combinam os níveis local, nacional e internacional. A ligação entre o discurso sobre a diversidade ou modelos nacionais de integração de minorias étnicas e a lógica em funcionamento dentro de escolas e salas de aula também tem atraído a atenção dos pesquisadores (BANKS, 2009). Mais recentemente, estudos têm mostrado interesse em aproveitar experiências nacionais para identificar fatores que levem a um melhor reconhecimento e valorização da diversidade cultural na educação. A situação específica de povos indígenas também foi explorada. Parece evidente que pesquisas comparativas maiores sobre essa questão são úteis, pois nos permitem contrastar os resultados de pesquisas sobre este tópico, comparar nossas 
metodologias e identificar práticas inovadoras que possam ser transferidas de um contexto a outro, ou mesmo internacionalmente. Além disso, o Hemisfério Sul, particularmente os países da América Latina e da Ásia, tem produzido estudos originais que devem ser compartilhados por pesquisadores baseados na Europa e na América do Norte.

Sem subestimar ou negligenciar a importância de políticas educacionais nacionais ou regionais no tratamento da diversidade cultural, esta seção do artigo visa a analisar e discutir a diversidade cultural nos sistemas educacionais a partir de uma perspectiva comparativa e internacional.

A diversidade cultural tem sido uma preocupação central para muitas organizações internacionais. Assim, desde os anos 1950, a Unesco tem colocado - e ainda coloca - essa questão no âmago de suas ações (LÉVISTRAUSS, 1952; UNESCO, 2010).

Lidar com a diversidade envolve tratar do estado de justiça, igualdade, democracia e discriminação:

\begin{abstract}
A Educação Multicultural refere-se às formas como todas as dimensões e aspectos da escolarização tratam das necessidades e talentos de populações culturalmente diversas, a fim de garantir igualdade e justiça social para todos. É tanto uma filosofia quanto um processo. Como conceito filosófico, está enraizada nos princípios da democracia, justiça social, igualdade e afirmação da diversidade humana. Como processo, a educação multicultural é fluida e passa continuamente por modificações para atender às necessidades e demandas de uma sociedade em permanente mudança. Para este fim, ela se torna uma estratégia integrada e um projeto educacional ou instrumento que emprega múltiplos saberes da história dos povos, e demonstra uma consciência de contextos (por exemplo, sociais, históricos), num esforço para enfrentar políticas de estado atuais que discriminam ou simplesmente ignoram pessoas, baseando-se em sua situação socioeconômica, raça, gênero, deficiência, religião e orientação sexual (GRANT, 2008, p. 9).
\end{abstract}

Revisando quatro periódicos proeminentes da literatura da área de educação durante dez anos nos Estados Unidos, Sleeter e Grant (1987) observaram que:

Raça, classe social e gênero tendem a ser tratados separadamente na literatura do campo da educação [...]. Uma não consideração da integração de raça, classe social e gênero leva, por vezes, a uma simplificação excessiva ou a uma compreensão imprecisa do que ocorre nas escolas, e, portanto, a prescrições simplistas ou inadequadas para a igualdade educacional (p.197).

A diversidade cultural na educação é um desafio internacional, não apenas porque a maioria das sociedades humanas é culturalmente diversa, mas também porque tal diversidade, se não for valorizada e tratada no sistema 
educacional, pode resultar em tensões e ameaças à coesão social.

Geralmente, há dois modelos principais para se lidar com a diversidade cultural. Primeiro, o modelo da assimilação, que considera que as diferenças culturais devem dar lugar à igualdade entre os cidadãos. Em segundo, o modelo multicultural, que oferece um direito à identidade cultural. Muitos estudos comparativos têm sido conduzidos nos últimos anos para determinar se esses modelos continuam dominantes ou se é observada alguma convergência.

Comparando os casos francês e sueco, Blanc-Noël (2010) apontou que as narrativas de identidades nacionais estão amplamente ligadas à forma como os dois países se adaptaram à aceleração da globalização. Na Suécia, era lógico estender os benefícios do estado de bem-estar social - o folkhemmet - a todos os cidadãos, independentemente de suas origens. A mudança de uma posição assimilacionista para uma posição multicultural pode ser vista como desenvolvimento e extensão de valores tradicionais, e não uma transformação radical. Quando a narrativa de identidade nacional incluía os valores interligados de bem-estar e internacionalismo, eles foram estendidos aos imigrantes na esfera doméstica. Era também uma implementação lógica de valores tradicionais de igualdade e solidariedade. A França, ao contrário, até o momento, jamais se considerou um país multicultural. A narrativa nacional francesa, elaborada sobre o propósito de manter diferentes povos juntos, não pode se permitir abrir as portas à diversidade. Os opositores do multiculturalismo são numerosos, e seu argumento preferido é que ele permitiria a criação de "comunidades" que colocariam a coesão da República em perigo. Entretanto, nos dois países, a narrativa de identidade nacional está sob discussão:

As narrativas nacionais foram construídas para responder a situações históricas. Hoje em dia, essas situações estão mudando mais rápido do que nunca. O caso sueco parece mostrar que uma brutal mudança de narrativa nacional não pode ter efeitos imediatos, enquanto a atitude francesa, que consiste em aferrar-se a uma narrativa obsoleta, não tem mais efeitos positivos. Além disso, os exemplos dos dois países mostram que tanto o multiculturalismo quanto o universalismo igualitário podem ter efeitos negativos para a coesão social nacional. Assim, ambos os países procuram antes encontrar um equilíbrio entre os direitos democráticos universais e o reconhecimento da diversidade. Para solucionar esse difícil desafio, está na hora de aprender as lições dadas pela história e, especialmente, por trabalhos sobre a história global. Eles mostram que a diversidade sempre foi constitutiva da história humana, e que estruturas de culturas sempre estiveram em movimento, em ritmos variados. Em um mundo globalizado, elas mover-se-ão e talvez desaparecerão ou fundir-se-ão um pouco mais rápido do que antes, mas o importante é que percebemos que a “mixidade" global foi uma sorte para a humanidade (BLANC-NOËL, 2010, p. 22).

Mesmo dentro de um mesmo país, como a França, há um fosso entre as 
diferentes opiniões sobre a diversidade. Greenwalt (2009) identificou duas práticas discursivas de identidade nacional por parte de estudantes franceses. Na primeira prática discursiva, rotulada como "republicana", os alunos empregam referências aos valores republicanos tradicionais de progresso revolucionário, ativismo político e busca objetiva por mecanismos que beneficiem o bem comum. Relacionam-se com seus professores de um modo em que estes são como mentores nos usos do poder institucional. Em contraste, um segundo grupo de narrativas de estudantes é centrado em um discurso de "reconhecimento social da diversidade". Esta segunda forma de falar tende a apresentar os professores como iguais socialmente, e implica, mais geralmente, que a França pós-colonial deveria aprender a se reconhecer como uma nação multicultural.

Outros pesquisadores destacam o aparecimento de um racismo que pode ser chamado de "racismo cultural", que se forma a partir de uma distância supostamente insuperável entre valores, inclusive religiosos. Por exemplo, Leeman e Reid (2006) identificaram diferenças interétnicas ligadas a uma hierarquia social operante na Austrália e nos Países Baixos. O que é consistente em ambos os contextos é uma forma cultural de racismo (culturalismo). De fato, em ambos os países, esse culturalismo parece estar cada vez mais focado na diferença religiosa. A situação na Austrália é ainda mais complexa considerando-se a posição marginalizada dos povos indígenas.

\begin{abstract}
As diferenças entre os países relacionam-se à rejeição da educação multicultural por parte dos povos indígenas em termos de suas próprias lutas e sua ocupação anterior da terra, e do fato de a educação multicultural ser vista como algo feito para imigrantes. Nos Países Baixos, é uma questão separada, mas somente professores em escolas com alto percentual de imigrantes se interessam. Na Austrália, o debate era altamente politizado até recentemente; a nova tendência na Austrália em direção à não tolerância, apesar da retórica do governo, tem silenciado essa questão. Nos Países Baixos, a educação intercultural é vista como importante para o respeito mútuo, e como útil à integração, mas a indiferença é evidente nas escolas. Isso provavelmente está relacionado a uma percepção, pelos holandeses, de que o tema seria pouco relevante para a cultura do país; um senso de relevância que, devido a um histórico de imigração, faz parte da cultura australiana (LEEMAN; REID, 2006, p. 67).
\end{abstract}

Como apontado por Sen (2006), o multiculturalismo mostra seus limites se privilegia a diferença a ponto de fixar as pessoas dentro de silos impermeáveis:

Haveria sérios problemas com as afirmações morais e sociais do multiculturalismo se ele for tomado no sentido de insistir que a identidade de uma pessoa deve ser definida por sua comunidade ou religião, desconsiderando todas as outras afiliações que uma pessoa possui [...] e ao atribuir prioridade automática à religião ou tradição herdada, acima da reflexão e da escolha (SEN, 2006, p. 160). 
Em última análise, a forma como a diversidade cultural é tratada no sistema educacional depende tanto da narrativa e dos mitos históricos da identidade nacional quanto das transformações socioculturais trazidas pela migração e globalização. Seguindo o processo de democratização dos anos 1980, e a crescente integração na economia global, o Brasil tem empreendido uma grande revisão de seu sistema educacional e uma melhoria da aceitação da diversidade cultural nas escolas.

\section{RELAÇÕES INTERÉtNICAS NO BRASIL: O LEGADO HISTÓRICO E O DESAFIO CONTEMPORÂNEO}

No sistema educacional brasileiro, a ideia de dar espaço à diversidade cultural é relativamente nova. Apesar da diversidade étnica e racial intrínseca à sociedade brasileira, abordagens interculturais surgiram somente há cerca de 15 anos. 0 país já vivenciou, sucessivamente, a escravidão e uma política de "branqueamento" da população, e, atualmente, os afro-brasileiros continuam sendo vítimas de desigualdade racial e social. Entretanto, nos últimos anos, temos visto o aparecimento de numerosas abordagens interculturais no sistema de ensino. Este artigo tenta situar as abordagens no contexto brasileiro e destacar suas perspectivas de desenvolvimento. Analisaremos a forte resistência que essas transformações encontram nas escolas. Essa oposição reflete a difícil conciliação que a abordagem intercultural tem de conquistar entre "o direito de ser diferente", por um lado, e o "imperativo da qualidade", por outro; entre "o tratamento igual entre os grupos étnicos" e o “sistema educacional nacional unificado". Isso pode dar lugar a um persistente paradoxo. No Brasil, todos vêm falando sobre interculturalismo nos últimos anos, e certas iniciativas legislativas têm buscado dar a ele um lugar adequado no sistema educacional. Porém, ainda é extremamente excepcional vê-lo na realidade cotidiana da sala de aula, pois ele reabre feridas, antagonismos e conflitos históricos que geram temores pela coesão nacional.

A história do Brasil está intimamente ligada à pluralidade étnica de sua população. De fato, à população ameríndia original juntaram-se os conquistadores portugueses, escravos da África e sucessivas ondas de imigrantes, principalmente europeus, mas também japoneses, sírio-libaneses e outros. Historicamente, essa pluralidade étnica e demograficamente estrutural foi moldada pela marginalização e dominação dos grupos étnicos de origem ameríndia e africana (SCHWARCZ, 2001). Os ameríndios foram objeto de uma empreitada de colonização e "civilização" que culminou, entre a época da conquista e hoje, em uma dramática queda de sua quantidade. 
O avanço constante da fronteira de colonização agrícola rumo ao interior, particularmente na Amazônia, tem reduzido gradual e consideravelmente seu espaço territorial. Embora a escravidão tenha sido abolida em 1888, os afrobrasileiros têm visto sua história e cultura sistematicamente desvalorizadas. Hoje, eles representam o grupo étnico mais afetado pela pobreza, violência urbana e exclusão social (D’ADESKY, 2001). Tal status de inferioridade se deve ao fato de que os afro-brasileiros, como ex-escravos, não foram capacitados para explorar sua liberdade; devido à sua falta de qualificação, bem como de recursos econômicos e culturais, eles automaticamente se tornaram parte da população socialmente excluída.

Tomando a análise da estrutura de relações entre brancos e negros como ponto de partida, Bastide e Fernandes (1955) trouxeram à luz desigualdades entre os segmentos branco e negro da sociedade brasileira. A ideologia branca parece considerar os negros como primitivos (sujos, feios, supersticiosos, financeiramente irresponsáveis, imorais, agressivos, pouco confiáveis no trabalho, sexualmente pervertidos e exibicionistas). Em uma sociedade multicultural e racialmente misturada como o Brasil, o sistema educacional sempre deu preferência à cultura branca, estabelecendo a desculturação e o "branqueamento" como seus objetivos (SILVA, 1987). A desculturação é um processo deliberado de desintegração cultural de um grupo com o propósito de sua exploração (colonial e neocolonial). "Branqueamento" é a aceitação da superioridade da raça branca, considerando seus valores, história e cultura como as únicas referências, e os únicos dignos de consideração. 0 branqueamento também encontra expressão na inferiorização dos valores dos grupos dominados.

Projetos políticos ditos "republicanos", como o de Caetano de Campos, sugeriam uma solução de transplante cultural, importando métodos de ensino, materiais e até pessoal com o intuito de transformar a raça brasileira. Como afirma Carvalho de Chagas (1989), a imigração europeia buscava não apenas substituir negros por brancos nos principais setores da produção, mas também elaborar um projeto de regeneração vocacional e treinamento cujo instrumento é a miscigenação interétnica e a finalidade última é o branqueamento moral da população negra.

Percebidos como inferiores, mas impossíveis de ser eliminados, esses dois grupos étnicos (afro-brasileiros e ameríndios) foram objeto de uma política oficial de assimilação visando a ancorar o país exclusivamente em sua herança cultural europeia. Na realidade, a ideologia do branqueamento visava a transformar o Brasil em uma nação branca, por meio de uma série de 
medidas concretas, em especial, pelo incentivo da imigração europeia. Essa transformação era percebida como pré-condição absoluta para se ter acesso à modernização, ou ao que, no Brasil, ainda hoje é chamado de "primeiro mundo". Paralelamente à ideologia e à prática da assimilação, surgiu um poderoso mito de uma "democracia racial” (miscigenação étnica) brasileira bem-sucedida entre os três grupos étnicos constituintes do país (ameríndios, africanos e europeus). Para Freyre (1933, 1952), principal proponente da democracia racial brasileira, o núcleo da coexistência harmoniosa entre esses três grupos tornou possível a fusão das três "raças”, apesar da experiência violenta de colonização e escravidão. O Brasil, segundo esta linha, é o único país do mundo onde diversas populações e culturas coabitam em harmonia.

O recente estudo de Nazaré Baía Coelho e Paiva Costa (2009) no estado do Pará mostrou a persistência, entre atores educacionais, do mito da democracia racial em sala de aula. As observações feitas em classe e a análise da linguagem dos professores e alunos refletem a legitimação da noção de um Brasil altamente miscigenado racialmente, o que constitui uma fonte de riqueza e orgulho nacional. No entanto, é preciso recordar que, já nos anos 1950, pesquisas realizadas pela Escola Paulista de Sociologia, com o apoio da Unesco, revelaram a magnitude da desigualdade racial no Brasil (BASTIDE; FERNANDES, 1955; IANNI, 1966; MAIO, 1999; FERNANDES, 1960). Conforme apontado por Fernandes (1960), a democracia racial é uma fachada que mascara uma ordem social desigual:

Uma democracia racial efetiva não existe no Brasil, onde as trocas entre indivíduos pertencentes a diferentes "raças" começam e terminam no nível da tolerância convencional.

Esta pode ser a "coisa certa" a fazer, satisfazendo-se as demandas de um questionável "espírito cristão" e a necessidade prática de "manter todos em seus lugares". Entretanto, ela não pode realmente aproximar mais os indivíduos, mas cria a base, dentro de um dado espaço social, da mera coexistência estritamente regulada por um código que legitima a desigualdade, encobrindo-a por trás de princípios de ordem social democrática (FERNANDES, 1960, p. xiv).

Após o retorno gradual da democracia nos anos 1980, o problema da desigualdade ligada à categoria racial ressurgiu em uma nova forma, pela pressão de movimentos associativos e de alguns intelectuais. Em 1995, o movimento negro brasileiro organizou, em Brasília, a marcha "Zumbi dos Palmares contra o racismo e a favor da cidadania e da vida". Essa demonstração, um marco na história das abordagens interculturais no país, apresentou ao então presidente brasileiro um documento exigindo não apenas o fim da discriminação racial, mas também medidas específicas para promover a igualdade racial. 
As relações étnicas e raciais no Brasil são extremamente complexas (REICHMANN, 1999). Embora o mito da democracia racial venha sendo cada vez mais contestado e a luta contra a discriminação racial seja, mais do que nunca, uma questão atual, as abordagens interculturais encontram forte resistência, conforme testemunhado pelo atual debate sobre ações afirmativas. A oposição, por vezes, está ligada ao papel desempenhado por governos estrangeiros, organizações internacionais e não governamentais (por exemplo, Unesco e Fundação Ford) na divulgação das abordagens interculturais. Tal papel é percebido por alguns brasileiros como uma interferência nos assuntos internos do país e como importação de questões não adaptadas ao contexto histórico brasileiro.

A questão da discriminação positiva não é o somente um debate técnico sobre indivíduos negros, brancos ou outros. É, sobretudo, uma questão social e política que tem, por muito tempo, impedido a minoria negra de se unir em torno de uma identidade étnica coerente. Como demonstrou claramente Sansone (2003), os afro-brasileiros não apenas não conseguiram se mobilizar como grupo étnico para obter igualdade de oportunidades como tampouco conseguiram enxergar-se como grupo distinto, porque muitos aspectos da cultura afro-brasileira penetraram profundamente na cultura brasileira como um todo. A música e a dança brasileiras são claros exemplos disso. Por muito tempo, uma genuína miscigenação da população brasileira neutralizou quaisquer demandas étnicas específicas. 0 valor da análise das abordagens interculturais no Brasil reside, precisamente, no paradoxo de uma sociedade multiétnica que não consegue se reconciliar com sua real diversidade, mas que, ao mesmo tempo, é extremamente distanciada dos modelos duais e bipolares de "brancos" versus "negros" dos Estados Unidos e da África do Sul, ou entre "nacionais" versus "imigrantes” na Europa. Daí o interesse das pesquisas em nível internacional sobre as abordagens interculturais ao focar no caso único representado pelo Brasil.

\section{A LEGISLAÇÃO A FAVOR DA INCORPORAÇÃO DA DIVERSIDADE CULTURAL NA EDUCAÇÃO}

Já de saída, é importante sublinhar o fato de que o retorno gradual da democracia na América Latina tornou possível, na maioria dos países da região, o aparecimento de demandas por parte de grupos culturais e étnicos dominados. Assim, nos anos 1980 e 1990, 11 países latino-americanos reconheceram em suas constituições o caráter multiétnico, pluricultural e multilíngue de suas sociedades (FERRÃO CANDAU; RUSSO, 2010). Como resultado, as políticas 
públicas no campo da educação têm tido progressivamente de encarar com seriedade o tratamento das diferenças culturais (FERRÃO CANDAU; RUSSO, 2010). No Brasil, discussões sobre a situação de grupos marginalizados na escola começaram nos anos 1970 e 1980, com o desenvolvimento do movimento pelos direitos civis dos afro-brasileiros, e com as primeiras investigações sobre estereótipos e discriminação no contexto educacional. Por um lado, as associações afro-brasileiras exigiam o pleno reconhecimento dos direitos dos afro-brasileiros. Levar em consideração a identidade cultural dos alunos afrodescendentes era então considerado indispensável para a melhoria de seus resultados educacionais. Por outro lado, pesquisadores educacionais documentaram de forma abundante a persistência, no ambiente escolar, de estereótipos em relação aos negros brasileiros, em particular com relação às representações nas mentes de professores e em materiais didáticos (PINTO, 1987a).

Em nível legislativo, o primeiro passo importante foi a Constituição Brasileira de 1988, que iniciou o progressivo retorno à democracia. Ela reconheceu a natureza cultural e racialmente composta e pluralista da nação brasileira. 0 artigo 215 reafirma a responsabilidade do Estado de proteger as expressões das culturas popular, indígena e afro-brasileira.

A seguir, a Lei de Diretrizes e Bases da Educação Nacional (LDB) de 1996 (Lei 9.394/96) instituiu um sistema educacional mais descentralizado, distribuindo a responsabilidade na área da educação entre União, estados e municípios. Essa lei estipulou, igualmente, a necessidade de fornecer aos alunos, em âmbito nacional, uma educação básica comum, mas também a necessidade de adaptar a escola a realidades locais e regionais (art. 26). Pela primeira vez, um direito de ser diferente conseguiu entrar na legislação educacional. Entretanto, a LDB assume a questão da diversidade cultural de forma geral e transversal, exceto com relação à atenção especial que ela dedica à educação bilíngue e intercultural de povos indígenas (artigos 78 e 79) (SARAIVA, 2010).

Um novo marco foi alcançado em 2003, com a aprovação da legislação que promove a educação intercultural. A Lei 10.639 introduziu o ensino obrigatório da história e cultura africana e afro-brasileira nos currículos oficiais primário e secundário. Pela primeira vez, a contribuição da comunidade negra na construção e formação da sociedade e identidade brasileiras era oficialmente exigida nos programas educacionais. Essa lei também introduziu o dia 20 de novembro no calendário escolar como Dia Nacional da Consciência Negra (SARAIVA, 2010). Em 2008, a Lei 10.639 foi convertida na Lei 11.645 , 
que reafirma a necessidade do ensino da história e cultura africana e afrobrasileira, e introduziu a história e cultura dos povos indígenas (SARAIVA, 2010).

\begin{tabular}{|c|c|c|}
\hline 1988 & $\begin{array}{l}\text { Nova Constituição } \\
\text { Brasileira }\end{array}$ & $\begin{array}{l}\text { - O dever do Estado de proteger as } \\
\text { expressões das culturas popular, indígena e } \\
\text { afro-brasileira. }\end{array}$ \\
\hline 1996 & $\begin{array}{l}\text { Lei de Diretrizes e } \\
\text { Bases da Educação } \\
\text { (LDB) }\end{array}$ & $\begin{array}{l}\text { - Descentralização da administração da } \\
\text { educação e necessidade de adaptar a } \\
\text { educação a realidades locais. } \\
\text { - Educação bilíngue e intercultural para } \\
\text { povos indígenas. }\end{array}$ \\
\hline 2003 & Lei 10.639 & $\begin{array}{l}\text { - Introdução do ensino obrigatório de } \\
\text { história e cultura africana e afro-brasileira } \\
\text { nos currículos dos níveis primário e } \\
\text { secundário. }\end{array}$ \\
\hline 2008 & Lei 11.645 & $\begin{array}{l}\text { - Confirmação do ensino de história e } \\
\text { cultura africana e afro-brasileira, e história } \\
\text { e cultura dos povos indígenas. } \\
\text { Quadro } 1 \text { - Principais datas e mecanismos } \\
\text { legais que promovem o aparecimento das } \\
\text { abordagens interculturais no Brasil. }\end{array}$ \\
\hline
\end{tabular}

Quadro 1 - Principais datas e mecanismos legais que promovem o aparecimento das abordagens interculturais no Brasil.

O Quadro1 mostra o tratamento específico às duas principais minorias étnicas com relação à introdução de abordagens interculturais no Brasil. Os ameríndios, devido ao seu pequeno número (menos de $1 \%$ da população brasileira) e sua presença geograficamente confinada, foram os primeiros beneficiários da abertura das escolas à diversidade cultural. Contrariamente, observa-se muita relutância com relação à afirmação da herança cultural afro-brasileira. Esse grupo constitui a maioria em algumas partes do país (Nordeste). Além disso, segundo estatísticas oficiais recentes, negros e mestiços representam a maioria da população do Brasil. Mesmo nas regiões do sul do país, às vezes consideradas como Brasil "branco", mestiços e afrobrasileiros têm sido parte da população por muitos anos.

Ademais, a super-representação de afro-brasileiros nas favelas tem motivado 
pesquisadores egestores a pensarque o problema racial seria automaticamente resolvido por ações mais vigorosas voltadas à eliminação da exclusão social e da pobreza. Estendendo essa análise a toda a América Latina, Hooker (2006) chega a falar de inclusão indígena e exclusão afrodescendente.

Em suma, a introdução da herança afro-brasileira no sistema educacional torna necessário repensar a identidade nacional brasileira e problematizála de forma diferente (CANEN, 2000). Repensar essa identidade implica, em particular, reconhecer a natureza mestiça de todo brasileiro, bem como a sedimentação da discriminação histórica contra afro-brasileiros e ameríndios. Isso, portanto, equivale a uma verdadeira revolução copernicana no esquema educacional brasileiro, originariamente concebido pelos jesuítas como um meio de assimilação de grupos “incivilizados” e de preparação da nação para o mundo moderno, exclusivamente visto como sendo europeu.

\section{Abordagens interculturais na FORMAÇÃo e nO trabalho dos PROFESSORES}

Utiliza-se um grande número de termos em iniciativas pedagógicas que buscam incorporar a diversidade cultural nos sistemas educacionais. Em alguns contextos, a expressão “educação multicultural” é utilizada; em outros, “educação intercultural”. Neste artigo, optamos pelo conceito de abordagens interculturais, na medida em que ele sublinha claramente o quanto esta área da educação é marcada por buscas e hesitações sobre a melhor forma de lidar com a diversidade cultural na escola (DASEN; PERREGAUX, 2000).

Procurando definir abordagens interculturais na formação e no trabalho dos professores no Brasil, usaremos a tipologia de Burnett (1994), que classifica tais abordagens em três categorias, segundo a ênfase principal em: (1) programas orientados para o conteúdo, (2) programas orientados para o aluno e (3) programas socialmente orientados. O Quadro 2 descreve as principais abordagens observadas no sistema educacional brasileiro. Ele mostra variedade tanto com relação às abordagens adotadas quanto com relação a seus iniciadores. Além de iniciativas relacionadas a currículo, as quais estão claramente presentes, nota-se a proliferação de dias comemorativos celebrando a herança cultural de vários grupos étnicos. Isso é reminiscente das comemorações criadas nos Estados Unidos, na esteira da introdução da educação multicultural (Dia de Martin Luther King, Mês da História Negra, Cinco de Mayo). 
A arte também é onipresente nas abordagens interculturais no Brasil. De fato, a arte pode ser considerada a espinha dorsal da cultura, uma vez que a dimensão artística é particularmente relevante para exercícios e experiências concretas de diversidade cultural em sala de aula. Os alunos geralmente gostam de aprender sobre as características das artes africana e indígena. Artesanato, músicas e danças aproximam os estudantes. Entretanto, o risco de apresentar tais culturas simplesmente como curiosidades transmitidas entre gerações, e assim reforçar a distância entre as culturas e os estereótipos, deve ser evitado.

\begin{tabular}{|c|c|c|c|}
\hline Ênfase & Descrição & $\begin{array}{l}\text { Elemento } \\
\text { desencadeador e } \\
\text { iniciadores }\end{array}$ & $\begin{array}{l}\text { Aplicação em sala de aula } \\
\text { e resistência observada }\end{array}$ \\
\hline Conteúdo & $\begin{array}{l}\text { Parâmetros } \\
\text { Curriculares } \\
\text { Nacionais. } \\
\text { Ensino de } \\
\text { história da } \\
\text { África e } \\
\text { dos povos } \\
\text { indígenas. } \\
\text { Ensino de arte e } \\
\text { cultura africana } \\
\text { e indígena. }\end{array}$ & $\begin{array}{l}\text { Legislação geral. } \\
\text { Ministério da } \\
\text { Educação. } \\
\text { Professores } \\
\text { de história e } \\
\text { geografia. } \\
\text { Professores de } \\
\text { artes (música, } \\
\text { dança, artes } \\
\text { visuais). }\end{array}$ & $\begin{array}{l}\text { Relativamente } \\
\text { desconhecida entre } \\
\text { professores em campo. } \\
\text { Deixada para iniciativas } \\
\text { individuais. } \\
\text { Os projetos mais bem- } \\
\text { sucedidos têm sido } \\
\text { aqueles ligados a projetos } \\
\text { baseados na escola } \\
\text { (conhecidos no Brasil } \\
\text { como “projetos políticos- } \\
\text { pedagógicos") ou } \\
\text { aqueles que incorporam a } \\
\text { dimensão artística. }\end{array}$ \\
\hline Aluno & $\begin{array}{l}\text { Educação } \\
\text { antirracista. } \\
\text { Educação } \\
\text { inclusiva. } \\
\text { Educação para } \\
\text { a cidadania. }\end{array}$ & $\begin{array}{l}\text { Movimentos } \\
\text { sociais. } \\
\text { Professores. } \\
\text { Ministério da } \\
\text { Educação. }\end{array}$ & $\begin{array}{l}\text { As abordagens } \\
\text { interculturais estão } \\
\text { integradas em inovações } \\
\text { educacionais mais } \\
\text { amplas. }\end{array}$ \\
\hline
\end{tabular}




\begin{tabular}{|c|c|c|c|}
\hline $\begin{array}{l}\text { Ação } \\
\text { social }\end{array}$ & $\begin{array}{l}\text { Dia de } \\
\text { comemoração } \\
\text { da Abolição da } \\
\text { Escravidão (13 } \\
\text { de maio). } \\
\text { Dia Nacional } \\
\text { da Consciência } \\
\text { Negra (20 de } \\
\text { novembro). } \\
\text { Dia do Índio (19 } \\
\text { de abril). } \\
\text { Formação de } \\
\text { professores } \\
\text { indígenas. } \\
\text { Implementação } \\
\text { de políticas de } \\
\text { discriminação } \\
\text { positiva e } \\
\text { cotas étnicas } \\
\text { em certas } \\
\text { instituições } \\
\text { educacionais. }\end{array}$ & $\begin{array}{l}\begin{array}{l}\text { Movimentos } \\
\text { afro-brasileiros e } \\
\text { indígenas. }\end{array} \\
\text { Ministério da } \\
\text { Educação. } \\
\text { Secretaria de } \\
\text { Políticas de } \\
\text { Promoção da } \\
\text { Igualdade Racial } \\
\text { (Seppir). }\end{array}$ & $\begin{array}{l}\text { } \\
\text { Políticas de promoção } \\
\text { do acesso à igualdade, } \\
\text { particularmente na } \\
\text { forma de cotas étnicas, } \\
\text { enfrentam resistência } \\
\text { de muitos lados, } \\
\text { motivadas pelos mitos } \\
\text { da democracia racial e do } \\
\text { mérito escolar. }\end{array}$ \\
\hline
\end{tabular}

Quadro 2 - Abordagens interculturais na formação e no trabalho dos professores.

Os Parâmetros Curriculares Nacionais ( $\mathrm{PCN}$ ) elaborados pelo Ministério Federal da Educação incentivam a integração da diversidade cultural na educação. 0 documento introdutório dos PCN para escolas primárias (BRASIL, 1997) enfatiza a necessidade de levar em conta a diversidade e de adaptar os objetivos, contextos e critérios de avaliação. A diversidade é um dos temas transversais que devem permear as várias disciplinas (língua portuguesa, matemática, história, geografia, ciências e artes), possibilitando, assim, a interdisciplinaridade no nível primário (KADLUBITSKI; JUNQUEIRA, 2009). 0 Ministério da Educação enfatiza que: 
Para viver numa sociedade democrática e pluralista, devemos respeitar e valorizar a

diversidade étnica e cultural da qual essa sociedade é composta. Em virtude de sua formação

histórica, a sociedade brasileira é marcada pela presença de vários grupos étnicos e culturais, e descendentes de imigrantes de diversas nacionalidades, religiões e línguas (BRASIL, 1998, p.

68).

Deve-se notar que a formação dos professores brasileiros nos últimos anos passou por amplas reformas, no sentido da formação universitária dos professores e de um maior profissionalismo. 0 espaço concedido às abordagens interculturais nessas reformas foi marginal, na medida em que elas não foram impostas como uma dimensão obrigatória e essencial. Parecem, antes, ter sido deixadas a iniciativas individuais da parte dos desenvolvedores e gestores de programas de formação. Frequentemente, as abordagens interculturais no currículo dos professores são colocadas sob a genérica classificação "guarda-chuva" da educação inclusiva, que, ao mesmo tempo, cobre a sensibilização às necessidades de alunos com deficiências e aqueles com barreiras à aprendizagem. Entretanto, a disponibilidade de recursos federais para a formação de professores indígenas motivou algumas universidades públicas a lançar programas de formação focados na valorização da diversidade (GRUPIONI, 2006).

$\mathrm{Na}$ medida em que o principal objetivo das abordagens interculturais na formação e no trabalho dos professores é mudar o comportamento dos atores educacionais com relação à diversidade étnica e cultural, será útil oferecer um breve panorama das pesquisas brasileiras sobre o tema.

Pinto (1987a) demonstrou a quase completa ausência de pesquisas lidando direta e especificamente com a educação de crianças negras e mestiças. Isso reflete a falta de estatísticas oficiais sobre identidade racial e étnica, dando a impressão de que o Brasil é um país monorracial. Nos círculos da pesquisa educacional, a falta de estudos que levam a cor em consideração também foi justificada pelo fato de a população negra estar concentrada nos níveis mais desprivilegiados da população brasileira (PINTO, 1987a). Para alguns pesquisadores, a cor da pele é coberta por estudos sobre pobreza e exclusão social.

Além desse velho debate sobre a dissolução da raça em categoria social, outros estudos tentaram analisar as representações transmitidas pelos materiais didáticos, uma vez que estes expressam o que uma sociedade considera digno de ser transmitido às futuras gerações. Tais recursos têm grande valor simbólico na valorização e desvalorização de diferentes grupos culturais (AKKARI; SAMPAIO, 2003). Cabe notar que as pesquisas brasileiras sobre este 
tópico mostram a persistência do racismo em materiais didáticos utilizados em sala de aula. Vários estudos já examinaram a representação dos negros nos livros escolares. Pinto (1987b), por exemplo, analisou o conteúdo de uma amostra de 48 livros utilizados na quarta série do nível primário, na região de São Paulo, entre 1941 e 1975. A análise das categorias étnicas baseou-se nos personagens que aparecem tanto no texto quanto nas ilustrações (1.378 personagens ilustrados e 4.449 personagens descritos). A comparação do status dos indivíduos brancos, mestiços e negros nas ilustrações mostra que os brancos estão, de longe, em posição de vantagem. São os mais numerosos ( $n=1.099$ ) e, em particular, monopolizam as partes estratégicas do livro, tais como as capas. A mulher negra nunca é retratada; ela é representada pela criada negra, com traços estereotipados bastante pronunciados. Os personagens brancos são mostrados com a maior diversidade, exercendo aproximadamente 36 tipos de atividades profissionais (incluindo as mais prestigiosas), enquanto negros e mestiços são mostrados em poucas atividades profissionais (incluindo as mais degradantes). Praticamente as mesmas observações acerca das capas são feitas sobre o texto.

Os livros didáticos, portanto, como principal veículo de aprendizado na educação formal, reforçam a imagem dos indivíduos negros como inferiores aos brancos. Contribuem para a confusão entre cor de pele e classe social. Quando a higiene é mencionada, a criança negra é mostrada como suja. Os livros didáticos constituem um instrumento de "construção de consciência" da inferioridade da raça negra (TRIUMPHO, 1987). Lino Gomes (2003) trouxe à luz a hesitação por parte do sistema educacional em aceitar e retratar o corpo negro de forma positiva, obrigando professores negros a encontrar outros espaços para assumir sua identidade racial. A mesma observação foi feita com relação às representações predominantes dos ameríndios, retratados como “selvagens”, “guerreiros” e “Índios!” (OLIVEIRA, 2003).

O pedagogo brasileiro Paulo Freire demonstrou o poder das imagens na educação (imagens do camponês, do trabalhador, do índio e do negro). Como linguagem visual, a imagem promove a comunicação humana e uma melhor compreensão da realidade dos alunos. A utilização de imagens artísticas melhora a experiência sensorial. A pedido de Paulo Freire, o artista Francisco Brennand criou uma série de dez imagens com figuras compostas de linhas e cores simples. Essas imagens, mostrando animais e certas atividades de trabalho e lazer (imagens retratando positivamente a interculturalidade), foram usadas de forma bem-sucedida em cursos de alfabetização. É de suma importância na educação fazer uso da sensibilidade e da afetividade, pois 
elas podem ser mais poderosas do que a racionalização cognitiva (POMPEU DA SILVA, 2009).

Uma investigação de Sampaio e Leite (2002) em uma escola localizada no centro histórico de Salvador é reveladora da forma como alunos negros suprimem desde cedo sua identidade racial. 0 professor de capoeira decidiu perguntar aos alunos de sua classe quem dentre eles era negro. Um simples olhar de relance para a classe era suficiente para se perceber que todas as crianças eram negras, mesmo que algumas fossem mais escuras do que outras. Todas as crianças, no entanto, disseram que não eram negras. Como o professor insistiu, alguns disseram que o pai dele era negro, mas nenhum deles era. As crianças integram muito cedo um senso de vergonha por sua cor de pele, seus corpos. Nas aulas seguintes, o professor de capoeira continuou seu questionamento, dirigindo-se a cada aluno individualmente: "Seu pai é negro? Sua mãe? E você?” Mesmo os alunos que responderam que o pai era negro, ou a mãe, recusaram-se a se identificar como negros. Depois de muita insistência, a classe acabou "acusando" uma das crianças da turma de ser negra!

Em seguida a mudanças legislativas significativas visando a promover as abordagens interculturais no sistema educacional e, em particular, na formação e no trabalho dos professores, poder-se-ia esperar que as conclusões de estudos mais recentes tivessem revelado mudanças de atitude por parte dos professores ou dos alunos brasileiros. Entretanto, esses estudos mostram uma continuada resistência por parte dos educadores às abordagens interculturais.

Em um projeto de pesquisa-ação realizado com professores do Rio de Janeiro, Canen (2007) observou a persistência de uma visão assistencialista da identidade cultural entre os professores. 0 mesmo estudo mostrou que a maioria dos professores não era sensível às desigualdades históricas às quais a população afro-brasileira estava submetida.

O estudo realizado por Nazaré Baía Coelho e Paiva Costa (2009) em uma escola no estado do Pará mostrou que os professores não têm conhecimento da questão étnica e racial, ou da lei 10.639/2003 sobre o ensino da história da cultura africana e afro-brasileira. Apenas um professor de história (negro e membro de um movimento social afro-brasileiro) estava familiarizado com o conteúdo dessa lei, e procurava implementá-la em classe. Assim, o interculturalismo não é apresentado como uma proposta pedagógica integrada ao sistema educacional de modo a efetivar a nova lei, mas, antes, uma posição isolada resultante das convicções pessoais de um professor. 0 
que se observou em sala de aula remete novamente ao mito das três raças mascarando o racismo que, de tempos em tempos, surge em piadas entre as crianças ou em lapsos de linguagem por parte dos professores.

O estudo de Santiago e Akkari (2010), atualmente em andamento no estado do Rio Grande do Norte, chegou às mesmas conclusões. Poucos professores entrevistados tinham ouvido falar das leis 10.639 ou 11.645 sobre a promoção de culturas de minorias nos currículos escolares. Além disso, os poucos professores que sabiam dessas mudanças legislativas tinham ouvido sobre elas por meio da mídia ou fora da escola.

A Unesco e o governo brasileiro traduziram e publicaram oito volumes dedicados à história africana. Materiais didáticos para professores e livros escolares para alunos também estão planejados, para que todos os recursos didáticos para o ensino de história africana estejam disponíveis dentro de um ou dois anos.

Em suma, por mais louváveis que essas mudanças legislativas possam ser, os esforços para introduzir abordagens interculturais no sistema educacional brasileiro ainda não produziram os resultados desejados na escolarização das minorias (SILVA; ARAÚJO, 2009). Eles constituem uma condição necessária, mas não suficiente, para traduzir intenções em atitudes e comportamentos interculturais.

\section{CONCLUSÃO}

0 artigo destacou dois aspectos do debate intercultural no Brasil. Primeiro, o país é permeável a discussões e experiências interculturais em nível internacional. Ele adotou uma série de medidas legislativas para promover o interculturalismo em sala de aula. A questão, agora, é ir além da abordagem legislativa, legal e comemorativa que atualmente predomina, e procurar ancorar o interculturalismo brasileiro em um processo de pensamento crítico que engaje as relações interétnicas cotidianas não apenas na escola, mas também na sociedade como um todo.

A nosso ver, os professores são as principais locomotivas para ultrapassar o atual conservadorismo e a prevenção do sistema educacional brasileiro com relação a abordagens interculturais. Consideramos que, para trazer uma mudança real ao tratamento da diversidade cultural, os professores devem ter uma visão mais ampla da educação intercultural, que é mais do que simplesmente saber sobre festividades, música, culinária e costumes típicos. 
Eles devem compreender a educação intercultural no contexto mais amplo da cidadania crítica e democrática, e não meramente fazer uma apreciação contemplativa das riquezas de vários grupos étnicos.

As abordagens interculturais são mediadas, no sistema educacional brasileiro, por duas estratégias principais. A primeira foca na reforma curricular, promovendo o reconhecimento da contribuição de grupos tradicionalmente oprimidos (afro-brasileiros e ameríndios). A segunda concentra-se em políticas de acesso à igualdade que dependem de um sistema de cotas étnicas e sociais para abrir acesso a certas instituições educacionais. Se a primeira estratégia ainda não encontrou muita resistência explícita, é porque ainda não se tornou cotidianamente efetiva em sala de aula. A segunda estratégia, no entanto, por desafiar o privilégio histórico de ser branco, tem levantado numerosas controvérsias que não devem se acalmar em breve. 


\section{Intercultural education in Brazil: between conservatism and radical transformations}

Abstract: This article attempts to analyse the emergence of intercultural education in the Brazilian educational system. First, we summarize the debate on international convergence in intercultural education. Second, we try to trace the development of interethnic relations in Brazil. The heavy legacy of slavery and colonization will be described. Then, the article addresses recently approved legislative measures to encourage the inclusion of cultural diversity in education. Finally, the text focuses on intercultural approaches in the training and work of teachers. The Brazilian example is interesting because it is characterized by both ongoing conservatism preventing intercultural legitimacy in schools but, at the same time, a profound debate about cultural identities and the need to take all historical inequalities into account.

Keywords: Intercultural education. Ethnic relations. Inequalities. Curriculum. 


\section{REFERÊNCIAS}

AKKARI, A.; SAMPAIO, S. Ethnicité et éducation interculturelle au Brésil. In: GOHARD-RADENKOVIC, A.; MUJUWAMARIYA, D.; PEREZ, S. (Ed.) Intégration des "minorités" et nouveaux espaces interculturels. Paris: L'Harmattan, 2003. p. 153-170.

BANKS, J. A. (Ed.). The Routledge International Companion to Multicultural Education. New York \& London: Routledge, 2009.

BASTIDE, R.; FERNANDES, F. Relações raciais entre negros e brancos em São Paulo. São Paulo: Anhembi, 1955.

BLANC-NOËL, N. Multicultural Sweden, assimilationist France: how and why national identity narratives evolve, 2010. Disponível em: 〈http://www.senspublic.org/article.php3?id_article=768>.

BRASIL. Parâmetros Curriculares Nacionais: primeiro e segundo ciclos do ensino fundamental. Documento introdutório. Brasília: MEC, 1997.

. Parâmetros Curriculares Nacionais: terceiro e quarto ciclos do ensino fundamental. Documento introdutório. Brasília: MEC, 1998.

BURNETT, G. Varieties of multicultural education: an introduction. Eric Digest. New York: Eric Clearinghouse on Urban Education, 1994.

CANEN, A. Educação multicultural, identidade nacional e pluralidade cultural: tensões e implicações curriculares. Cadernos de Pesquisa, n. 111, p. 135-149, 2000.

Multiculturalism and a research perspective in initial teacher education: possible dialogues policy. Futures in Education, n. 4, p. 519-534, 2007.

CARVALHO DE CHAGAS, M. A escola e a República. São Paulo: Brasiliense, 1989.

COELHO, W. N. B.; PAIVA COSTA, R. Representações sobre relações raciais na sala de aula: o negro no cotidiano escolar. Educação (UFSM), n. 2, p. 326-337, 2009.

D’ADESKY, J. Racismes et antiracismes au Brésil. Paris: L’Harmattan, 2001.

DASEN, P. R.; PERREGAUX, C. (Ed.). Pourquoi des approches interculturelles en sciences de l'éducation? Bruxelles: De Boeck, 2000. 
FERNANDES, F. Prefácio. In: CARDOSO, F. H.; IANNI, O. Cor e mobilidade social em Florianópolis. São Paulo: Companhia Editora Nacional, 1960.

FERRÃO CANDAU, V. M.; RUSSO, K. Interculturalidade e educação em América Latina: uma construção plural, original e complexa. Revista Diálogo Educacional, n. 29, p. 151-169, 2010.

FREYRE, G. Casa grande e senzala. 25 ed. Rio de Janeiro: J. Olympio, 1933 [1987].

Maîtres et esclaves. Paris: Gallimard, 1952.

GRANT, C. A. The evolution of multicultural education in the United States: a journey for human rights \& social justice. INTERNATIONAL CONFERENCE 'COOPERATIVE LEARNING IN MULTICULTURAL SOCIETIES: CRITICAL REFLECTIONS, 2008, Turin. Anais... Turin: International Association for Intercultural Education, 2008.

GREENWALT, K. A. Discourse, narrative, and national identity: the case of France. Harvard Educational Review, v. 79, n. 3, p. 494-519, 2009.

GRUPIONI, L. D. B. (Ed.). Formação de professores indígenas: repensando trajetórias Brasília: MEC/Unesco, 2006.

HOOKER, J. Inclusão indígena e exclusão dos afrodescendentes na América Latina. Tempo Social, n. 2, p. 89-111, 2006.

IANNI, O. Raças e classes sociais no Brasil. Rio de Janeiro: Civilização Brasileira, 1966.

KADLUBITSKI, L.; JUNQUEIRA, S. Diversidade cultural e políticas públicas educacionais. Educação, n. 1, p. 179-194, 2009.

LEEMAN, Y.; REID, C. Multi/intercultural education in Australia and the Netherlands. Compare: A Journal of Comparative and International Education, v. 36, n. 1, p. 57-72, 2006.

LÉVI-STRAUSS, C. Race et histoire. Paris: Unesco, 1952.

LINO GOMES, N. Educação, identidade negra e formação de professores/as: um olhar sobre o corpo negro e o cabelo crespo. Educação e Pesquisa, n. 1, p. 167-182, 2003.

MAIO, M. C. Projeto Unesco e a agenda das ciências sociais no Brasil dos anos 
40 e 50. Revista Brasileira de Ciências Sociais, n. 41, p. 141-158, 1999.

OLIVEIRA, T. Olhares que fazem a 'diferença': o índio em livros didáticos e outros artefatos culturais. Revista Brasileira de Educação, n. 22, p. 25-34, 2003.

PINTO, R. A educação de negro: uma revisão da bibliografia. Cadernos de Pesquisa, n. 62, p. 3-34, 1987a.

A representação do negro em livros didáticos de leitura. Cadernos de Pesquisa, n. 63, p. 88-92, 1987b.

POMPEU DA SILVA, C. A arte como expressão da liberdade: o corpo e as expressões artísticas no pensamento de Paulo Freire. 2009. Dissertação (Mestrado em Educação)-Pontifícia Universidade Católica do Paraná, Curitiba, 2009.

REICHMANN, R. (Ed.). Race in contemporary Brazil: from indifference to inequality. State College, PA: Penn State University Press, 1999.

SAMPAIO, S.; LEITE, R. N. Relatório Anual do Projeto Mestre Pastinha. Salvador: Departamento de Psicologia FFCH/UFBa, 2002. Mimeografado.

SANSONE, L. Blackness without ethnicity: constructing race in Brazil. New York: Palgrave McMillan, 2003.

SANTIAGO, M.; AKKARI, A. A promoção da diversidade cultural no contexto escolar: das intenções legislativas às práticas escolares. COLÓQUIO INTERNACIONAL EDUCAÇÃO E CONTEMPORANEIDADE, 2010, Sergipe. Anais... Sergipe: Universidade Federal de Sergipe, 2010.

SARAIVA, S. La politique curriculaire au Brésil: entre valorisation de la diversité culturelle, prise encompte des mémoires particulières et construction d'une histoire commune: analyse des instructions officielles (1988-2008) in Brazil: In: CARPENTIER, C.; RIARD, E-H. (Ed.). Vivre ensemble dans les sociétés multiculturelles. Paris: L'Harmattan, 2010.

SCHWARCZ, L. M. Racismo no Brasil. São Paulo: Publifolha, 2001.

SEN, A. Identity and violence: the illusion of destiny. New York: Norton and Co., 2006.

SILVA, A. C. da. Estereótipos e preconceitos em relação ao negro no livro de comunicação e expressão do 1 ํㅡ grau - nível 1. Cadernos de Pesquisa, n. 63, p. 96-98, 1987. 
SILVA, P. B. G.; ARAÚJO, S. S. O. Achieving quality education for Indigenous people black in Brazil. In: BANKS, J.A. (Ed.). The Routledge International Companion to Multicultural Education. New York; London: Routledge, 2009. p. 526-539.

SLEETER, C. E.; GRANT, C. A. An analysis of multicultural education in the United States. Harvard Educational Review, v. 57, n. 4, p. 421-444, 1987.

TRIUMPHO, V. R. O negro no livro didático e a prática dos agentes de pastoral negros. Cadernos de Pesquisa, n. 63, p. 93-95, 1987.

UNESCO. Investir dans la diversité culturelle et le dialogue interculturel. Paris: Unesco, 2010.

\section{Sobre o autor:}

Abdeljalil Akkari é professor e diretor de um grupo de pesquisas sobre educação internacional na Universidade de Genebra. Atua também como consultor para a Unesco e outras organizações internacionais

abdeljalil.akkari@unige.ch 